\title{
The new policy sciences: combining the cognitive science of choice, multiple theories of context, and basic and applied analysis
}

\author{
Paul Cairney ${ }^{1} \cdot$ Christopher M. Weible $^{2}$
}

Published online: 8 November 2017

(C) The Author(s) 2017. This article is an open access publication

\begin{abstract}
It is time to imagine a new policy sciences. The policymaking world has moved on since its first design. So too has our understanding of it. The original policy sciences were contextualized, problem-oriented, multi-method, and focused on using scientific research towards the realization of greater human dignity. We introduce a new policy sciences that builds on such aims. We describe the need for realistic depictions of 'rational' and 'irrational' choice, multiple theories to portray the multifaceted nature of complex contexts, and the combination of applied and basic research. To set this new agenda, we build on two foundational strategies: identifying advances in the psychology of decisionmaking and describing how policy theories depict policymaking psychology in complex contexts.
\end{abstract}

Keywords Bounded rationality · Complexity · Policy sciences · Policy process · Policy analysis · Public policy

\section{Introduction}

Among the gems in Herbert Simon's scholarship is the analogy of the ant (Simon 1996). Simon describes a squiggly line which represents a path that an ant traverses from one side of a beach to another. He then asks: why is the line squiggly, not straight? The path reflects the knowledge, strategies, and adaptive ability of the ant, using trial-and-error learning across a complex and ever-changing context. The ant does not have a bird's eye view of the

Paul Cairney

p.a.cairney@stir.ac.uk

Christopher M. Weible

chris.weible@ucdenver.edu

1 Division of History and Politics, University of Stirling, Stirling, UK

2 School of Public Affairs, University of Colorado Denver, Denver, CO, USA 
beach, cannot foretell how it will change, and does not know where its goal lies, but it reaches its endpoint nonetheless. Simon provides a near-perfect analogy of people engaged in politics and the policy process. They have a goal, such as a change in policy, but they do not know exactly how to achieve it. They have imperfect cognition to inform their decision-making and an imperfect understanding of their context. ${ }^{1}$

Inspired by Lasswell $(1951,1971)$, policy scholars can help these people on their journey by using: (1) psychology and cognitive science to describe the art of choice, in which people use reliable short cuts to gather information to make good enough decisions and (2) multiple policy process theories to describe a policy context's ever-changing complexity. The best way we can do this is to (3) combine applied and basic science in the field.

In this essay, we present a provocative story of the policy sciences since the days of Lasswell. At its heart is our argument that the depiction of the old policy sciences still offers some inspiration, but it has not kept pace with new models of human choice and theories of the policy process. This problem has resulted partly from the unintended consequence of Lasswell's distinction between 'knowledge of' and 'knowledge in' the policy process, which has produced an unnecessary split between basic and applied research. In others words, there is a major gap between the ways in which we develop and use policy process theories and policy analysis tools. Consequently, policy analysis research is often conducted with an insufficient appreciation of basic science, and policy process research is often esoteric and detached from practice.

Our depiction of a new policy sciences updates the language of the old to focus more on choice and contexts and embrace applied and basic science in conducting policy analysis and policy process research. In this essay, we highlight two ways to do so: know your policymaker audience and the context in which they operate. For example, policymaker attention is fleeting and they engage emotionally with information, which limits the impact of a lengthy evidence-based analysis and puts the onus on policy analysts to tell a simple persuasive story. Further, given the changing landscape and the multitude of choices facing people engaged in the policy process, single-shot solutions will not work. Therefore, our best strategy as policy scholars is to offer people ways to think critically to help them learn and adapt while making their choices and navigating the policy process. Throughout, we should remember the goal of our efforts: to achieve a greater realization of human dignity and political equality.

\section{The old policy sciences}

In his presidential address to the American Political Science Association, Lasswell (1956) encouraged his colleagues to take a practical turn. Lasswell $(1951,1971)$ championed the 'policy sciences' as a new field of study for the advancement of society and the realization of greater human dignity, particularly towards democratic ideals. For Lasswell, the conduct of the policy sciences consisted of the integration of policy analysis and the policy process. Policy process research provided the contextualization of a problem, and policy analysis provided the problem-oriented advice. For example, a policy scientist might analyse a situation to understand its various decision and social dimensions (policy process research)

\footnotetext{
1 Throughout this essay we refer to a policy 'environment' or 'context'. We use both terms to describe, very broadly, the circumstances in which people find themselves. We use more specific terms such as 'institution' or 'network' to describe key parts of that environment (see Heikkila and Cairney 2017).
} 
and then estimate trends and impacts while providing advice to a decision maker (policy analysis). Such a study would be guided by the policy science framework (Lasswell 1971).

After Lasswell first presented his vision, many political scientists resisted his calling, partly because political science was trying to transform itself into a basic science wherein the combination of descriptive and prescriptive analysis was viewed as potentially tainting its scientific integrity. Lasswell and his followers continued to implement their vision independent of many political scientists (Brewer 1974; Lasswell 1971; Brewer and deLeon 1983 Deleon 1997; Clark 2002). Nevertheless, a rift developed between basic and applied sciences, and most scholars did not integrate policy analysis and policy processes (Ranney 1968; Sabatier 1992). Today, people mostly use the term 'policy sciences' to refer vaguely to the field of public policy. We have also long since moved beyond the policy sciences framework and key components such as the policy cycle. Even though scholars cite or pay tribute to Lasswell, his original vision has been watered down to a few normative messages. Moving forward requires a new vision that is more relevant to today's challenges.

\section{The new policy sciences}

A new policy sciences needs to incorporate policy analysis and policy process research. Broadly speaking, policy analysis provides the study of client-oriented advice in assessing past policies or recommending future policies (Bardach and Patashnik 2015; Weimer and Vining 2017). It is designed for people actively participating in the policy process, populated with decision-making tools, such as cost-benefit analysis, that are understood and used by practitioners. It is not informed routinely by policy theory.

In contrast, policy process research can be defined as the study of the patterns and interactions surrounding public policy over time. Theories usually focus on building knowledge about the characterizations of policy systems, subsystems, and decision-making venues rather than producing practical advice amenable to specific decisions. Policy process research is populated with many theories, which serve as the medium within which knowledge is built, stored, and advanced. The audience for these theories tend to be academics, and policy process theorists have struggled to translate strategies from their science into practice. There is clear potential to do so (Weible and Cairney 2018; Weible et al. 2012; Cairney 2015, 2016; Shipan and Volden 2012), but most efforts are halfhearted and ineffective. For example, writing policy implications in the conclusion of articles-published in academic journals that are inaccessible to policymakers, because they are behind a paywall and an opaque language-guarantees limited impact (deLeon and Weible 2010).

What would a new policy sciences look like? It would perform three functions.

\section{Broaden the spectrum of choice and the people involved}

The old policy sciences focuses too much on the policy decision and a small group of policymakers. Consequently, in policy analysis, we might estimate the future effects of a policymaker selecting between solutions using Bardach and Patashnik's (2015) Eightfold Path. Yet, policy selection is one of many choices, and there are many more types of actors in the policy process than 'policymakers', and the process does not have a beginning or end. For example, people engage in numerous decisions that span all notional stages of the policy cycle, such as forming and maintaining coalitions, venue shopping, telling 
persuasive stories, and establishing the right frame for analysis. Therefore, the new policy sciences should focus on the myriad of choices by many people in a fluid and ongoing policy process.

\section{Show how choice takes place in complex contexts}

The context in which we study policymaking changes across space and time. Its complexity and dynamism poses important challenges. An effective narrative that sways public opinion by one advocacy group in one case may not work in another and one policy solution that works in one context can fail in another. The solution is not to give up on lesson learning and generalizability, but to emphasize the shifting context and often ephemeral nature of our recommendations. For policy scholars, the best we can do for people engaged in the policy process is to offer multiple theoretical depictions of the context, and our best portrayal of its dynamics, and emphasize the pros and cons of the ways in which people can adapt and learn to achieve their goals (Sanderson 2009).

\section{Embrace basic and applied science}

Lasswell's distinction between policy process research as basic science, and policy analysis as applied science, is artificial. For example, the Institutional Analysis and Development framework helps integrate a strong contextualized component in analysing collective action and in evaluating its outcomes (Ostrom 2005). Additionally, recent work on 'policy bubbles' brings an evaluative component to patterns of policymaking overtime under punctuated equilibrium theory (Jones et al. 2014). More generally, most policy scholars now recognize the value of doing applied and basic research, even if they do one or the other. There are fewer calls to maintain a theory and practice divide and more opportunities to embrace applied and basic orientations.

\section{How do we make the most of a new policy sciences?}

Step 1 Learn from psychology and cognitive sciences to improve our model of choice.

Originally, models of choice were based on a rejection of the notion of perfect rationality. Put simply, there can be no 'comprehensive rationality' in which policymakers can understand their context fully and process all policy-relevant information, to turn their values into a coherent and consistent set of objectives. Rather, they possess incomplete information and face 'bounded rationality', or a limited ability to process information and use it to produce consistent policy preferences (Simon 1957, 1976; Lindblom 1959; Jones 1999; John 2012; Cairney 2012a: 96).

Consequently, they use two short cuts to gather enough information to make good enough decisions in a context that often limits their time to think before acting: rational, by pursuing sufficiently clear goals and prioritizing certain kinds and sources of information, and irrational, by drawing on emotions, gut feelings, deeply held beliefs, habits, and what is familiar to them, to make decisions quickly (Cairney 2016).

Notionally, people process information as individuals, but in reality we make calculations based on our interactions with others. For example, our value orientations can change following interactions with people who reinforce or challenge our beliefs (Wildavsky 1987). Further, the major premise of Simon's behavioural rationality was that: 'humans do 
have priorities and goals, but they are not generally effective in judging the connections between those goals and the complex reality they face' (Jones and Thomas 2017: 49). Therefore, we need to understand the relationship between (a) the ways in which people set policy goals, including the role of irrationality in their mental calculus, and (b) their context, which they only partly understand and influence.

Bounded rationality has been ever-present in modern policy scholarship, but only recently have policy scholars drawn so heavily from social and organizational psychology to understand how emotions act as informational short cuts and coexist with cognition. Modern reference points include Haidt's (2001: 818, 2007, 2012) distinction between 'intuitive system' and 'reasoning system' and Kahneman's (2012: 20) thinking 'fast and slow'. Lewis (2013: 4; 7) argues that 'fast' thinking is 'typically where the action is' because people conserve 'attention and cognitive processing capabilities for the few activities we currently view as most essential' and rely on 'autopilot' whenever emotions are heightened. Studies of 'processing fluency' suggest that individuals' decisions are influenced by their familiarity with things; the ease in which they process information (Alter and Oppenheimer 2009: 220). Organizational psychology also highlights the importance of 'social context' and 'group processes', which often inhibit an organization's ability to 'liberate' the knowledge provided by each person and broaden the 'information considered before making a decision' (Larrick 2016).

Modern policy theories incorporate such developments, in their scientific study of policymaking, by identifying: the role of emotion and stories in attention to policy problems (Jones 1999; McBeth et al. 2014), the impact of emotional decision-making during the social construction of target populations (Schneider and Ingram 1997), and the tendency of members of advocacy coalitions to romanticize their own cause and demonise their opponents (Sabatier 1988).

But what are the implications for the new policy sciences? The lessons for policy analysis can be profound and should prompt us to reconsider how to present an evidenceinformed case. Policy analysts have always known the value of some responses to human cognition. For example, the exhortation to keep policy analysis short, minimize jargon, and favour concrete examples over an abstract problem, is based generally on the need to minimize the cognitive load on your audience (Winne and Nesbit 2010). Yet, consider if policymakers feel antagonism towards a person giving what they perceive to be dubious evidence without realizing they are 'carrying' a group emotion with them (Menges and Kilduff 2015). A sole focus on cognitive load is futile if policymakers have a reason to not pay attention to an issue at all or to reject the analysis completely because they find it threatening.

Further, if people engage emotionally with information, there is no way to appeal to all audiences with the same information. Rather, policy analysts face dilemmas about the extent to which they are willing to anticipate policymaker psychology, engage with a group emotion while telling a simple story with a clear moral, and weigh up the strategy of 'speaking truth to power', which may backfire if the audience does not trust the storyteller, versus rallying the audience by reinforcing their core beliefs (Cairney and Kwiatkowski 2018). In any case, policy analysis is inherently political, not an objective relay of the evidence (Cairney 2016). The choice is not whether or not to focus on skilful persuasion which appeals to emotion, but how to do it most effectively while adhering to key ethical principles.

Step 2 Consider how policy advice is used in complex contexts.

This focus on psychology-driven choice takes place largely at the micro-level or 'model of the individual' (Heikkila and Cairney 2017). The complexity of such choices increases 
exponentially with the complex nature of the policymaking context. It is tempting in policy analysis to assume that we know who our audience is and what the context might be. Yet, policy processes take place in a context out of the control of any single person. A policymaker's environment consists of a myriad of actors and factors: multiple policymakers and influencers spread across levels and types of government; the formal and informal institutions that guide their actions at each level; the networks they form; the ideas or beliefs that dominate the ways in which they think about problems and solutions; the biophysical and socio-economic conditions to which they respond; and the events that offer opportunities and shocks. Therefore, psychological studies built on 'knowing our audience' have limited applicability if they do not build on our knowledge of a large and messy policy environment in which audience can change quickly.

The significance of these insights differs markedly according to our aims. First, the scientific study of context prompts us to make choices about how to combine realistic assumptions of human psychology with analysis that is simple enough to be modelled at scale (Jones and Thomas 2017). We may all be unique individuals with complex patterns of thought and action, but no model of collective choice can incorporate such levels of individual complexity (Jones 2001; Hindmoor 2010). Our aim is to strike the right balance between simple analysis, to avoid a too-messy link between cognitive and contextual explanations for action, and complex analysis of cognition, to avoid treating all thought in the same way and therefore reduce all explanation to environmental factors (Jones 2017: 64; Hay 2004). Another aim is to articulate convincingly the iterative relationship between individual actors and the organizations and wider contexts in which they operate. So far, this effort has enjoyed limited success (Jones 2017: 63).

While conducting policy analysis, we are more interested in what to do in the face of complexity. Policy analysts in the policy process are akin to Simon's ants, enjoying some degree of system-level knowledge, but facing high levels of uncertainty. At this level of analysis, we can identify useful but problematic advice from complexity theory (Geyer and Cairney 2015; Teisman and Klijn 2008: 288; Cairney 2012b: 349; Sanderson 2009). In short, it warns us not to expect 'law-like behaviour and the idea that evidence of success in one context will mean success in another', highlighting the role of 'emergence ... in the absence of central government control, which makes it difficult to know how, and to whom, to present evidence and to predict the impact of evidence-based policy' (Cairney 2016: 39). Such insights should prompt policy analysts to seek multiple audiences because policy influence and responsibility is diffused. It could also prompt central government policymakers to let go of the idea that they can control policy outcomes. Yet, it is difficult to know how seriously a policy analyst will be taken if they base their advice on a rejection of the main ways in which we hold elected policymakers to account (Cairney 2015). Just as the study of individual/system-wide cognition remains incomplete, so too does the study of how to present pragmatic policy analysis effectively.

Second, the study of meso-level policy processes offers more useful—albeit generaladvice for policy analysis. Before we dispense advice, it prompts us to find out who is most active and interested, because most policymakers ignore most issues most of the time (Baumgartner 2017). Consequently, the action is usually at the subsystem, not system, level. Further, by focusing on institutions, as the formal and informal rules guiding behaviour in organizations, we highlight the need to couch advice in terms of their standard operating procedures. Or, by identifying the role of ideas, we show that a simple policy analysis narrative only makes sense in relation to a deeper or more widespread narrative of the problem, described variously as paradigms, hegemons, or core beliefs (Heikkila and Cairney 2017). Each example points to the same implication: focus on engagement for the 
long term to develop the resources necessary to maximize the impact of policy analysis and understand the context in which the information is used. Among the advantages of longterm engagement are learning the 'rules of the game' in organizations, forming networks built on trust and a track record of reliability, learning how to 'soften' policy solutions according to the beliefs of key policymakers and influencers, and spotting 'windows of opportunity' to bring together attention to a problem, a feasible solution, and the motive and opportunity of policymakers to select it (Cairney et al. 2016; Weible et al. 2012; Kingdon 1984). In short, the substance of your analysis only has meaning in relation to the context in which it is used. Further, generating trust in the messenger and knowing your audience may be more important to success than presenting the evidence.

\section{Conclusion}

What is the best way to structure the policy sciences? We need to direct our basic and applied science towards realistic depictions of choice in complex contexts. We cannot make people more rational, but we can establish that their choices come from a mix of rationality and irrationality and help people adapt accordingly. We cannot make their context simpler, but we can offer multiple theoretical descriptions of its complexity and explanations of its key dynamics.

The biggest contribution of the new policy sciences is to encourage critical thinking. Scholars can help actors in the policy process to ask better questions, identify their own assumptions and cognitive filters and biases, see the world through different viewpoints, recognize the strengths and limitations of their information searches and networks, and better specify the source of their successes and failures. Above all else, we can dispense with the idea of comparing real-world policymaking with the myth of comprehensively rational action, to advise people not to give up their bounded and irrational minds but to look for opportunities to learn and adapt their strategies to better achieve their goals. To make it happen, we need to recognize the combined value of basic and applied science.

Undergirding the new policy sciences is one simple motto: 'know your audience and their context'. At the level of the individual, we are only beginning to scratch the surface of what makes people tick; to identify their ways in which they engage emotionally with information and combine facts and emotions to make decisions. Similarly, at the context level, although we know that all audiences are embedded in decision-making venues, policy subsystems, and political systems, and that we can use policy theories to make sense of complexity, we also recognize that each theory only captures one piece of the puzzle. Therefore, we highlight a new agenda but recognize that we do not yet have the knowledge to ensure complete success.

This essay provides key ideas on what the new policy sciences should grow into. The limitations of the past include an artificial separation of 'knowledge of' and 'knowledge in', a narrow overemphasis on policymaking rather than the multitude of choices in the policy process, and our inability to embrace multiple theories to explain the complex dynamics of policymaking in a coherent way. Future studies of the new policy sciences should be built on a small number of key tenets: the policy process is too complex to fully understand, and it contains many people trying various strategies to better respond to a continuously changing context.

Such complexity rules out a 'general theory' of policy processes; any theory captures only one face of the multifaceted context. It rules out any single policy analysis tool that 
might provide advice from one value orientation. It rules out overly simplified models of the individual that ignore the role of emotions, the functionality of heuristics, and the complexity of the human mind. Finally, it puts more onus on the policy scholar to up their game: describe, explain, and prescribe a foundation of knowledge that can be used to give policy advice; and show policymakers and influencers that their primary hope for success hinges on their ability to learn and adapt. Only then we can live up to Lasswell's normative vision to direct our science towards greater human dignity and political equality.

Open Access This article is distributed under the terms of the Creative Commons Attribution 4.0 International License (http://creativecommons.org/licenses/by/4.0/), which permits unrestricted use, distribution, and reproduction in any medium, provided you give appropriate credit to the original author(s) and the source, provide a link to the Creative Commons license, and indicate if changes were made.

\section{References}

Alter, A., \& Oppenheimer, D. (2009). Uniting the tribes of fluency to form a metacognitive nation. Personality and Social Psychology Review, 13(3), 219-235.

Bardach, E., \& Patashnik, E. M. (2015). A practical guide for policy analysis: The eightfold path to more effective problem solving. Washington, DC: CQ Press.

Baumgartner, F. R. (2017). Endogenous disjoint change. Cognitive Systems Research, 44, 69-73. https://doi. org/10.1016/j.cogsys.2017.04.001.

Brewer, G. D. (1974). The policy sciences emerge: To nurture and structure a discipline. Policy Sciences, $5(3), 239-244$

Brewer, G. D., \& DeLeon, P. (1983). The foundations of policy analysis. Chicago, IL: The Dorsey Press.

Cairney, P. (2012a). Understanding public policy. Basingstoke: Palgrave.

Cairney, P. (2012b). Complexity theory in political science and public policy. Political Studies Review, 10, $346-358$.

Cairney, P. (2015). How can policy theory have an impact on policy making? Teaching Public Administration, 33(1), 22-39.

Cairney, P. (2016). The politics of evidence-based plicymaking. London: Palgrave Pivot.

Cairney, P. \& Kwiatkowski, R. (2018). How to communicate effectively with policymakers. Palgrave Communications, (in press).

Cairney, P., Oliver, K., \& Wellstead, A. (2016). To bridge the divide between evidence and policy: Reduce ambiguity as much as uncertainty. Public Administration Review, Early View. https://doi.org/10.1111/ puar. 12555 .

Clark, T. W. (2002). The policy process: A practical guide for natural resources professionals. New Haven, CT: Yale University Press.

deLeon, P. (1997). Democracy and the policy sciences. Albany, NY: SUNY Press.

deLeon, P., \& Weible, C. M. (2010). Policy process research for democracy: A commentary on Lasswell's vision. International Journal of Policy Studies., 1(2), 22-34.

Geyer, R., \& Cairney, P. (Eds.). (2015). Handbook of complexity and public policy. Cheltenham: Edward Elgar.

Haidt, J. (2001). The emotional dog and its rational tai. Psychological Review, 108(4), 814-834.

Haidt, J. (2007). The new synthesis in moral psychology. Science, 316, 998-1000.

Haidt, J. (2012). The righteous mind: Why good people are divided by politics and religion. New York: Pantheon.

Hay, C. (2004). Theory, stylized heuristic or self-fulfilling prophecy? Public Administration, 82(1), 39-62.

Heikkila, T., \& Cairney, C. (2017). Comparison of theories of the policy process. In C. M. Weible \& P. A. Sabatier (Eds.), Theories of the policy process (4th ed.). Boulder, CO: Westview Press.

Hindmoor, A. (2010). "Major combat operations have ended?" Arguing about rational choice, 1994-2009. British Journal of Political Science, 41(1), 191-210.

John, P. (2012). Analysing public policy (2nd ed.). London: Routledge.

Jones, B. (1999). Bounded Rationality. Annual Review of Political Science, 2, 297-321.

Jones, B. (2001). Politics and the architecture of choice. Chicago, IL: University of Chicago Press.

Jones, B. (2017). Behavioral rationality as a foundation for public policy studies. Cognitive Systems Research, 43, 63-75. 
Jones, B., \& Thomas, H. (2017). The cognitive underpinnings of policy process studies'. Cognitive Systems Research, 45, 48-51.

Jones, B. D., Thomas, H. F., \& Wolfe, M. (2014). Policy bubbles. Policy Studies Journal, 42(1), 146-171.

Kahneman, D. (2012). Thinking fast and slow (UK ed.). London: Penguin.

Kingdon, J. (1984). Agendas, alternatives and public policies. New York, NY: Harper Collins.

Larrick, R. P. (2016). The social context of decisions. Annual Review of Organizational Psychology and Organizational Behavior, 3, 441-467.

Lasswell, H. D. (1951). The policy orientation. In D. Lerner \& H. D. Lasswell (Eds.), The policy sciences: Recent developments in scope and methods. Stanford, CA: Stanford University Press.

Lasswell, H. D. (1956). The political science of science. American Political Science Review, 50(4), 961-979.

Lasswell, H. D. (1971). A pre-view of the policy sciences. New York: American Elsevier Publishing.

Lewis, P. (2013). Policy Thinking, Fast and Slow, American Political Science Association 2013 Annual Meeting Available at SSRN: http://ssrn.com/abstract=2300479.

Lindblom, C. (1959). The science of muddling through. Public Administration Review, 19, 79-88.

McBeth, M., Jones, M., \& Shanahan, E. (2014). The narrative policy framework. In P. Sabatier \& C. Weible (Eds.), Theories of the Policy Process (3rd ed.). Chicago: Westview Press.

Menges, J. I., \& Kilduff, M. (2015). Group emotions: Cutting the gordian knots concerning terms, levels of analysis, and processes. The Academy of Management Annals, 9(1), 845-928. https://doi.org/10.1080/ 19416520.2015.1033148.

Ostrom, E. (2005). Understanding institutional diversity. Princeton, NJ: Princeton University Press.

Ranney, A. (1968). The study of policy content. In A. Ranney (Ed.), Political science and public policy (pp. 3-21). Chicago, IL: Markham Publishing Company.

Sabatier, P. A. (1988). An advocacy coalition framework of policy change and the role of policy-oriented learning therein. Policy Sciences, 21(2), 129-168.

Sabatier, P. A. (1992). Political science and public policy: An assessment. In W. Dunn \& R. M. Kelly (Eds.), Advances in policy studies (pp. 1950-1990). Brunswick, N.J.: Transaction Books.

Sanderson, I. (2009). Intelligent policy making for a complex world. Political Studies, 57, 699-719.

Schneider, A. L., \& Ingram, H. M. (1997). Policy design for democracy. Lawrence: University Press of Kansas.

Shipan, C. R., \& Volden, C. (2012). Policy diffusion: Seven lessons for scholars and practitioners. Public Administration Review, 72(6), 788-796.

Simon, H. (1957). Models of man. New York, NY: Wiley.

Simon, H. (1976). Administrative behavior (3rd ed.). London: Macmillan.

Simon, H. (1996). The sciences of the artificial (3rd ed.). Cambridge, MA: The MIT Press.

Teisman, G., \& Klijn, E. (2008). Complexity theory and public management. Public Management Review, 10(3), 287-297.

Weible, C. M., \& Cairney, P. (2018). Practical lessons from policy theories, Policy and Politics, (in press).

Weible, C., Heikkila, T., deLeon, P., \& Sabatier, P. (2012). Understanding and influencing the policy process. Policy Sciences, 45(1), 1-21.

Weimer, D. L., \& Vining, A. R. (2017). Policy analysis: Concepts and practice. London: Routledge.

Wildavsky, A. (1987). Choosing preferences by constructing institutions: A cultural theory of preference formation. American Political Science Review, 81(1), 3-21.

Winne, P. H., \& Nesbit, J. C. (2010). The psychology of academic achievement. Annual Review of Psychology, 61(1), 653-678. https://doi.org/10.1146/annurev.psych.093008.100348. 